\title{
The Social Media Revolution:
}

\section{Sharing and Learning in the Age of Leaky Knowledge}

\author{
Paul M. Leonardi \\ Technology Management Program \\ UC Santa Barbara \\ Leonardi@tmp.ucsb.edu
}

(c) 2017. This manuscript version is made available under the Elsevier user license http://www.elsevier.com/open-access/userlicense/1.0/ 


\begin{abstract}
This paper suggests that social media may be useful for knowledge sharing because they are leaky pipes for communication - the directionality and content of a particular message is visible to people not involved in it. However, social media are only useful for knowledge sharing if some people contribute knowledge that can leak from them and others retrieve knowledge that is leaking. I draw on interviews with employees from a financial services firm to develop a typology of reasons why new employees would not want to contribute what they know to a social media or retrieve from it knowledge contributed by others. Then, I use existing theory on knowledge sharing in organizations, coupled with recent writings about social media affordances, to develop propositions about how these barriers to knowledge sharing might be effectively overcome through strategic use of the social media affordances themselves.
\end{abstract}

Key Words: Social Media, Knowledge Sharing, Communication, Affordances, Contribution, Retrieval 


\section{The Social Media Revolution:}

\section{Sharing and Learning in the Age of Leaky Knowledge}

Managing knowledge is hard work. If managing knowledge means that the right people in an organization have the right knowledge at their disposal at the right time, knowledge management entails, at a very minimum, convincing people who develop knowledge to share it with others and convincing people who need it to find it and use it. More than two decades of research into knowledge management has shown that people need a lot of convincing. Despite exhortations to do so, the number of people who actually contribute their knowledge to communal systems that could benefit others in the organization remains quite low (Cress, Kimmerle, \& Hesse, 2006). It seems that people just don't like documenting what they know and contributing that documentation to some system (Heinz \& Rice, 2009). Also, people who need knowledge often don't know it. If they do know they need it, they often don't know whether it exits somewhere in the organization for them to find (Choi, Lee, \& Yoo, 2010). If they do know it exists, they often express a preference to ask other people for it rather than go to the databases where it is stored (Yuan et al., 2010). Given all this complexity and lack of enthusiasm, it appears that systems of knowledge management in organizations may need an overhaul.

In the last few years, a number of scholars have begun to suggest that use of social media within organizations may represent such an overhaul (Ellison, Gibbs, \& Weber, 2015; Jarrahi \& Sawyer, 2013; Leonardi, 2014). Not only are social media new tools through which knowledge sharing can occur - affording behaviors that make it easy to identify and communicate with experts (Leonardi \& Vaast, 2017; Majchrzak et al., 2013) - they portend to change the process 
by which knowledge management unfolds. Their ability to effect such change has to do with their leakiness.

Although the particular features of the various technologies like blogs, social networking sites, social tagging sites, and wikis that constitute the category of social media are all somewhat different, they share at least two underlying affordances (Treem \& Leonardi, 2012). First, they make people's communication with each other visible for third parties to see. People not involved in a specific communication between two others can literally see what those people communicated to each other. Second, those communications persist over time as threads that reflect the context in which they emerged. The result of these affordances is that communication about routine work matters between people can (by design) leak out of the channel and into other people's streams of awareness. Typical modes of mediated communication used in organizations such as email, instant messaging, memos do not have this leaky property. Less technologically mediated forms of communication such as hallway conversations do, but their reach is typically limited to a few feet around those in conversation.

If one believes that knowledge is produced and enacted through talk and action (Leonardi \& Rodriguez-Lluesma, 2012; Nicolini, Gherardi, \& Yanow, 2003; Orlikowski, 2002), then those communications that leak out of social media are, by definition, leaking knowledge. It is with this realization in hand that scholars have begun suggesting that social media may stand to revolutionize the way knowledge sharing happens in organizations and, consequently, they way organizations might think about managing knowledge. This is the perspective that Kane (2017) takes in his interesting essay on the promise of social media for knowledge management. In it, Kane (2017: XXXX) argues for the link between social media, leakiness, and knowledge:

Knowledge is leakier than ever. In the previous generation of KM, managers were concerned that IT tools would allow valuable knowledge to "leak" across organizational 
boundaries (Brown and Duguid 2001). In many ways, mobile social media is a KM system ideally suited for leaking knowledge.

He goes on to argue that the most "impactful outcome" of such leakiness may well be people's "ready access to mundane details of life inside the company." Leonardi, Huysman, and Steinfield (2013) also argue that such leakiness is a characteristic of social media. As they suggest:

Using the metaphor of a leaky pipe we mean to suggest that the directionality of a particular communication (to whom it is directed) and the content of that communication (what the parties involved actually said to each other) is visible to people who were not involved in it. Although the message may be communicated for an intended audience, many others for whom the communication was not intended can learn that two people are communication partners and what it is that they communicated about because the technologies make not only the message public, but indicators of who the sender and recipients are as well. (p. 7)

Because social media make communication public, even messages directed to a particular audience can be seen or heard by others in the organization. In other words, the pipes through which the communication travels are not watertight; instead (by design), they leak the knowledge contained in them out to a wider and often unknown audience.

This characteristic of leakiness has the potential to upend the way we think about managing knowledge within organizations. The dominant model of knowledge management tied to the use of knowledge management systems reads like an idealized sequenced of events: someone generates knowledge in the practice of her work, she encodes that knowledge into a document, she uploads that document to a shared repository, someone deciding that he needs knowledge goes to the repository and downloads the document, he reads the document and decodes the knowledge so he can apply it to his work. The model promised by social media and outlined by Kane (2017) as well as others looks much different and, in fact, much simpler: in the course of their normal work people communicate with each other and those communications 
produce knowledge, someone stumbles upon those communications and reads them and their context cues and learns either the knowledge, who has certain knowledge, or both.

As this new model would have it, people do not have to go to the extra work of trying to abstract knowledge from practice (which scholars often argue cannot be done anyway (Nicolini, 2012)), put it in some repository, and wait for others to find it and try to re-contextualize it so they can use it. Instead, people simply communicate as they always have, just through a different channel. As Leonardi (2014) argues, this new practice of knowledge sharing via social media use removes the burden of effort from the person who has the knowledge and places it on the person who needs the knowledge. The person who has knowledge can simply communicate as he or she has always done about routine tasks and not have to be concerned about summarizing those tasks, reflecting on what knowledge was used to conduct them, codifying those thoughts into some document, uploading it to some database and advertising that it is there. The burden on the person hoping to receive knowledge is also greatly reduced since that person has only to observe other people's communications and, through such observation of ambient communication, will become aware of relevant knowledge (Leonardi, 2015). In such model there is no need to download documentation and try to re-contextualize it in a projected version of the practice in which it might have been produced. Instead, people who stumble upon third-party communications that are visible and persistent in social media can participate vicariously in the very conversation that produced knowledge and, in effect, become an actor in the (re)production of that knowledge him or herself. Such a new model of knowledge sharing would, of course, require us to rethink how we manage knowledge. Consequently, as Kane (2017) argues, in an era of leaky knowledge, "the promise of effective KM as a key organizational competency first envisioned decades ago are far from dead and - in fact - may still only be in its infancy (p. XX) 
Of course, social media will only achieve such promise if some people are contributing knowledge that can leak from them and, conversely, if other people are retrieving the knowledge that is leaking. In what follows, I begin with a discussion of the types of knowledge that can be produced through the use of social media. Next, I draw on interviews with new employees from across six divisions of a major financial services firm to develop a typology of reasons why individuals would not want to contribute what they know to social media or retrieve from them knowledge contributed by others. I then turn to the body of research on knowledge sharing in organizations to consider, in a general sense, how some of these barriers can be overcome effectively. I develop propositions about how these research findings might be actualized through the use of affordances particular to social media implemented within organizations. The goal of this project is to extend Kane's (2017) argument about the role of social media in an era of leaky knowledge by beginning to build theory about how the affordances of social media themselves may be used in ways that encourage practices of contribution that will enable knowledge to leak, and practices of retrieval that will ensure that the knowledge that does leak leaks where it provide the greatest benefit.

\section{Knowledge Leakiness}

Over the years, organizations have adopted various kinds of computer-mediated technologies in the hopes that these tools would make the process of knowledge sharing easier and, consequently, more likely to occur. Technologies such as discretionary database, intranets, and most recently, knowledge management systems, were each believed to hold the promise of more effective knowledge sharing among employees. It is interesting to note that most technologies created and implemented with the explicit goal of increasing knowledge sharing attempt to do so by creating forums in which individuals knowingly present their knowledge to 
others in a public forum. For example, an employee who wishes to share with others what he knows about customer preferences in a particular demographic or engineering specifications for a particular product create some kind of formal document, report, or brief summarizing their knowledge and post it to the database, intranet, or knowledge management tool for others to read, download, and use in their work (Leonardi \& Treem, 2012). This explicit summarization of knowledge in preparation for public presentation makes so-called "knowledge management technologies" distinct from more traditional computer-mediated communication technologies like the telephone, email, instant messaging, or password controlled shared folders, which are traditionally used for semi-private communication (Alavi \& Leidner, 2001). In other words, employees typically use the phone, email and other tools to communicate directly with an intended audience. People may indeed share knowledge with one another when using communication technologies of this type, but they do so with an understanding of who their audience is, and they are usually aware that most other people in the organization know neither with whom they are communicating nor what the content of the communication is.

From research on the use of social media outside the workplace, we know that such tools are often used like traditional computer-mediated technologies (Ehrlich \& Shami, 2010; Lenhart et al., 2010). Such similarities in patterns of use notwithstanding, social media are different from traditional computer-mediated communication technologies in at least one important way: they make one's direct communications public by showing it to a wider audience. (Erickson \& Kellogg, 2000; Treem \& Leonardi, 2012). When someone communicates to others through email, the telephone, or an instant messaging application they can be reasonably confident that they are using a watertight pipe for message transmission. Unless the recipients of a message actively share it with others, the content of that message and even the knowledge that a 
communication occurred between the sender and the receiver(s) are invisible to other people. But when people communicate with others directly through social media (think about wall postings on social networking sites or the threaded structure of comments in blogs) both the directionality of their communication (to whom they are communicating) and the content of that communication (what they say to each other) are visible to others who stumble upon it. Of course, social media are not the only technologies that make people's daily communications visible to third parties. Treem and Leonardi (2012: 149) document a number of communication tools (e.g. email, bulletin boards, knowledge management systems) that can make some aspects of workplace communication visible to others. But as the authors show through their analysis of the literature, social media like social networking sites, blogs, and wikis, make routine communication more visible, more often, and with less effort than most any other kind of communication tool. Consequently, people's communications are more likely to be visible to third-parties when they occur through a social media tool than when they occur through any other kinds of communication technology (Farrell, Kellogg, \& Thomas, 2008; Holtzblatt \& Tierney, 2011).

For these reasons, directional communication through social media is like communication through a leaky pipe. Although the message may be communicated for an intended audience, many others for whom the communication was not intended can learn that two people are communication partners and what it is that they communicated about because the technologies make not only the message public, but indicators of who the sender and recipients are as well. Surely, there are some circumstances in which employees want or need the content of their communication and awareness of who their communication partners are to remain private. But 
from the standpoint of organizational knowledge sharing, directional communication through leaky pipes may be quite advantageous for the organization, writ large.

One way in which communication through leaky pipes can be beneficial for knowledge sharing is that it can help employees learn important direct knowledge. For example, if an employee in the operations department is assigned with a supply chain optimization task he may not know what parameters are important to consider in his model. If, upon reviewing contributions to a social media tool, he sees that two employees in his department had a series of discussions about a prior attempt at supply chain optimization and shared links to documents with each other, he can read their communications and examine the documents to learn how to parameterize his model. If the two employees had not communicated with one another through the social media tool, but had used email instead, the person in question would likely have no awareness that this communication took place and would not be able to see the content of the communication and the link to the supporting documents. In this case, the person would have had to guess at model parameters or ask around until he found one of the two employees and hoped that they remembered they created this document and where they stored it. Such direct learning from people and documents has been shown to be an important mode of knowledge sharing in organizations (Huber, 1991). But research shows that direct learning is often impeded because people simply do not know what knowledge exists out there to be learned, or where that knowledge lies (Wenger, 2000). They do not have an awareness of what knowledge exists in the organization because it has been communicated through watertight pipes. Because prior communications may contain important knowledge in them, social media tools, by virtue of their leakiness, can allow employees access to such knowledge so they can learn it directly. 
Another way in which the leaky pipes provided by social media can be beneficial to organizational members is that even if they do not learn directly from the communication, visibility into who other people communicated with and what they communicated about may help them learn important meta-knowledge (Leonardi, 2014). In other words, by seeing who communicates with whom about what, people begin to build knowledge about who knows what. Researchers interested in knowledge sharing in organizations have shown that the development of meta-knowledge is an important antecedent of successful knowledge sharing among employees (Yuan et al., 2010). As one example of a way in which the leaky pipes of social media may help employees to develop meta-knowledge quickly, imagine a new employee to marketing who needs to extract data on consumer purchasing behavior from the company's datacenter. As a new employee, she might be aware that the datacenter has this information, but not have insight about who to contact to access it. If, when reviewing content on the social media tool, this employee sees that a colleague in marketing has talked with someone in the datacenter, she begins to develop meta-knowledge. Because she knows that the colleague in marketing knows someone at the datacenter, she can ask the colleague in marketing if this is the correct person from whom to obtain the data she needs. Were the communication between the colleague in marketing and the person in the datacenter to happen through a watertight pipe like the telephone, the new employee would not have been able to easily and quickly develop the metaknowledge necessary to obtain the information with which to complete her assignment.

That social media often leak the directionality and content of communication gives them some important affordances similar to face-to-face communication that are lost through the use of more traditional computer-mediated communication tools. Lave and Wenger (1991) argued for the importance of situated learning in organizations and occupations. They suggested that 
doing particular work tasks in the co-presence of others was essential for a people to learn the knowledge to be able to do work effectively and to become an insider in a community. Their argument was based on the notion of legitimate peripheral participation, which suggested that individuals who sat on the sidelines watching others perform particular tasks and communicate with others learned by seeing and hearing what was done and said and who was doing and saying what. Their well-cited studies of midwives, tailors, butchers, and non-drinking alcoholics showed that physical proximity allowed communication between others to be seen and heard by others and it is through such intended and unintended spillover that knowledge sharing happened. Similarly, by leaking the directionality and content of a communication to an unknown audience, social media may allow individuals to conduct the voyeuristic activities necessary to learn from others.

However, in order to realize the potential benefits social media could provide for knowledge sharing with and among employees requires that people are contributing their knowledge to the technology by engaging in directed communication with a coworker and then retrieving knowledge from the technology by reading and reflecting upon that directed communication between others. Thus, the first major research question this paper asks is: What reasons do organizational members give for not wanting to contribute knowledge to and retrieve knowledge from a new social media? Following this, the second research question asks: How might employees and managers use the affordances provided by social media to overcome these barriers to knowledge contribution and retrieval? To answer the first question, I report on findings from interviews with newly hired employees at a major financial services firm and link these emergent findings to existing literature on knowledge sharing in organizations. To move toward an answer for the second question, I combine research on organizational knowledge 
sharing with research on social media use in organizations to develop propositions about how particular practices that may encourage increased knowledge sharing.

\section{Methods}

\section{Data Collection}

The data for this study were collected at a large financial services firm headquartered in the Midwestern United States. American Financial (a pseudonym) is a major direct banking and payment services company. Since its inception in 1986, the company has become one of the largest credit card issuers in the U.S. The credit card issuing side had receivables of more than \$46 billion in 2011 and the deposits side of the company had $\$ 18$ billion in consumer deposits and originated more than $\$ 5$ billion in personal and student loans.

In early 2010, the Director of Internal Communication at American Financial began working with an external software vendor to customize a social media platform for communication among employees. The platform would combine social networking capabilities with profile pages, walls, and associated algorithms for suggesting new contacts - with blog and wiki technologies and a shared document repository where items could be tagged and linked to a user's profile page or wall. The platform also had capabilities for group discussion forums and shared group folders. As the Director for Internal Communications commented, the goal of the social media, which was branded as A-Life (short for "American Life"), was to increase organizational knowledge sharing. Although executives at American Financial did not plan to roll out the new social media to employees until mid 2012, they began actively advertising ALife to employees in Fall 2011.

In December of 2011, the research team, consisting of me and three graduate students trained in ethnographic interviewing techniques, conducted interviews with 60 employees from 
across six divisions at American Financial: Marketing, Operations, Analytics, Finance, Business Technology, and Customer Strategy. Each of these employees graduated from college in 2011 and began as a full-time employee in a leadership rotation program in one of the divisions in July 2011. Each employee was responsible for completing a six-month rotation in three of the division's departments during their first 18 months of employment. Because all of the employees were new to the organization, and because they were required to rotate through three different departments, most viewed knowledge sharing as essential for success at the company. I chose to study young employees who were hired directly out of college because the literature suggests that it is this demographic that is most likely to embrace social media tools in the workplace (Chui et al., 2012). Thus, if even these young employees voice concerns about wanting to use social media in the workplace, older and longer tenured employees would likely be even more adverse.

We interviewed every employee hired into the six divisional leadership rotation programs in 2011. Each interview lasted between 40 and 70 minutes, with an average length of 50 minutes. The interviews followed the same semi-standard protocol (Kvale, 1996) that was comprised of four major sections. In the first section, we asked general information about the informant's background and past work experience. Questions such as "What do you do in your job?" and "What does it take to be successful in your current role?" were aimed at soliciting from informants their opinions of the skills necessary to do their work. In the second section, we asked specific questions about knowledge use at work. Questions like, "What type of knowledge do you think is most important for being a good____ (insert job title)?” and "Are some people at American Financial more knowledgeable in certain areas than others?" were meant to encourage informants to discuss their needs for knowledge to complete their work. The third section asked 
them about how the retrieved knowledge from and contributed knowledge to others. Questions like "How do you know where to go to get the knowledge you need?" and "How do you make the decision to share knowledge you have with others?" were intended to capture informant's strategies for knowledge seeking and sharing. Finally, the fourth section asked them specific questions about various technologies they used at home and at work, their perceptions about social media generally, and their perceptions about if and how they would use A-Life for knowledge sharing at work. With the consent of the informants, all interviews were audiorecorded and later transcribed verbatim.

\section{Data Analysis}

Because the first research question asked what reasons employees give for not wanting to contribute knowledge to and retrieve knowledge from a new social media technology, I began data analysis with a process of theoretical coding. Glaser (1978), suggests that theoretical coding is a useful strategy when the analyst has a concept he or she is looking to learn about by examining the data. Accordingly, I culled the interview transcripts to identify reasons given about why informants would and would not want to contribute knowledge through use of a social media, generally, or A-Life, specifically and then I placed codes on these reasons. Through this process, I generated 23 codes representing reasons informants gave about why they would not want to contribute knowledge to a social media and I generated 19 codes representing reasons given about why informants would not want to retrieve knowledge from a social media.

The next step of analysis - axial coding - involved putting the coded data back together in new ways by grouping codes that were conceptually similar (Strauss \& Corbin, 1998). Axial coding resulted in the reclassification of data into six larger categories of reasons why informants did not want to contribute knowledge and five larger categories of reasons why informants did 
not want to retrieve knowledge. The six categories of reasons for not wanting to contribute knowledge were fear, laziness, perceptions of inequality, loss of control, misunderstandings, and time pressure. The five categories of reasons for not wanting to retrieve knowledge were unawareness, impersonal nature of information, distrust, overload, and memory.

Finally, during the process of selective coding (Strauss \& Corbin, 1998). I sought to integrate all codes from the process of axial coding into specific categories that portrayed a coherent representation of the main phenomena of interest. Selective coding was considered complete when theoretical saturation was obtained; that is, when no new or relevant data informed a category, when the category development was densely populated, and when the relationships between categories were supported by ample data. Through this process, I uncovered three major reasons that informants felt they would not contribute their knowledge to a social media: (1) Lack of incentive, (2) Ease of free riding, and (3) a belief that one's own knowledge was not useful to others. I uncovered two major reasons that informants believed that they would not want to readily retrieve knowledge that was contained in a social media: (1) Lack of awareness of knowledge and (2) Preference for information from people known to them.

Because the second research question asked how employees and managers might use the affordances provided by social media to overcome the identified barriers to knowledge contribution and retrieval, I turned to the existing literature on knowledge sharing in organizations in search of evidence about what practices are effective. After linking the relevant theory to explain why the barriers I uncovered in the qualitative analysis exist and persist over time, I looked for literature to explain what theoretical mechanisms are useful for helping to overcome them in a general sense. I then used these evidence-based insights to reflect on the various affordances of social media outlined by Treem and Leonardi (2012) (e.g. visibility, 
editability, persistence, and association) and develop propositions about how encouraging specific ways of using social media itself might help to overcome these barriers. Based on this process of comparing my empirical findings with existing evidence from the literature, I developed propositions about how certain uses of social media might help to overcome each barrier.

\section{Barriers to and Opportunities for Knowledge Contribution and Retrieval}

This section presents the findings of the qualitative research on barriers to knowledge contribution and retrieval. After presenting each barrier, I discuss the relevant literature and present propositions about potential solutions. Table 1, summarizes the main argument in this section by presenting the empirically identified barriers to knowledge sharing in organizations and highlighting the potential for social media to help overcome them.

\section{INSERT TABLE 1 ABOUT HERE}

\section{Knowledge Contribution}

Lack of Incentive. Because all informants were new to American Financial and were faced with beginning a new job every six months, they nearly unanimously recognized the benefits of knowledge sharing with more senior employees in the company and with others in the divisional rotation program. Most informants felt a strong incentive to share what they knew with others because they depended upon a norm of reciprocity. As one employee from the Business Technology division commented, "If you don't share knowledge with people no one's probably going to share it with you." If informants could not easily find the knowledge necessary to complete their work tasks, they risked receiving low performance evaluations and could potentially lose their jobs. Consequently, informants indicated that there was a broad incentive to share knowledge with others so as to be sure they received knowledge they needed in return. 
Although most informants felt compelled to share knowledge with coworkers, they differed in their options about whether any incentive existed to contribute knowledge they had learned in their work to a social media like A-Life by sending a directed communication to someone else, by posting documents upon which they had worked, or by writing summaries of how to complete work tasks they had completed and posting them on group wikis. Table 2 indicates the differences in informants' perceptions about whether they felt any incentive to contribute their own personal knowledge to A-Life. Interestingly, informants who had positive general perceptions of the role social media could play in the work place perceived that lack of incentive was a low barrier to contributing knowledge to a technology of this kind. However, informants who held neutral or negative perceptions to social media's role in the workplace perceived that lack of incentive was a high barrier to contributing knowledge. ${ }^{1}$

\section{INSERT TABLE 2 ABOUT HERE}

In the emerging literature on social media use in organizations, at least one study has shown that adding an incentive system (e.g. individuals earned visible points and badges for content contributions to profiles) to a corporate social networking site increased employee contributions and users commented that they monitored and compared their standing relative to coworkers (Farzan et al., 2008). In a study of nine large organizations, Gammelgaard (2007) found that when managers simply made public acknowledgements that they appreciated and valued particular knowledge contributions made in staff meetings or made to databases, individuals were more likely to contribute again and people who did not contribute were more likely to begin. Incentives can come in the form of peer recognition as well as from management.

\footnotetext{
${ }^{1}$ I repeated this analysis of placing informants into categories based on whether they perceived that using social media at work was positive, neutral, and negative. Out of the three barriers to knowledge contribution and the three barriers to knowledge retrieval found in this study, the lack of incentive barrier was the only barrier that showed any noticeable difference in perceptions based on the category into which informants fell. For this reason, I do not present a corresponding table for any of the other barriers discussed below.
} 
The evidence suggests that individuals are also likely to contribute knowledge of work processes and systems when they perceive that doing so increases their personal or professional status within a social group (Leonardi \& Rodriguez-Lluesma, 2013; Wasko \& Faraj, 2005).

Because activity conducted on social media is public, there may be ample opportunities for managers and coworkers to use recognition-based incentives to encourage knowledge contributions. For example, when an individual communicates a piece of knowledge with someone else in the organization through the use of a social media that communication is visible for others to see. Managers and coworkers can easily recognize the choice to communicate through a leaky pipe by posting a comment on the communication exchange that indicates his or her approval, such as "this is a really good piece of information you've shared." They can also signal the usefulness of contributed knowledge by using a recognition-based feature such as a "like" button to signal that knowledge is useful For example, research has shown that blog use by one's manager was associated with greater likelihood of individual blog use (Wattal, Racherla, \& Mandviwalla, 2009). The benefit, of either a management or colleague recognition of this kind is two-fold. First, due to the way most social media are materially configured, the contributor will receive some type of notification (e.g. an email or update) indicating that his post was commented upon or liked so he or she will know people are paying attention. Second, and perhaps more importantly, those recognitions, because they are public, are available for others to see, which can encourage more contributions. Research suggests that public recognition of a particular activity is a powerful motivator of more activity of the same type in the future (Holtzblatt, Damianos, \& Weiss, 2010). Given these arguments, I advance the following proposition:

Proposition 1: $\quad$ For individuals who need intrinsic incentives to contribute knowledge to social media, public affirmations on their knowledge contributions 
by managers and/or coworkers in the form of commenting on or "liking" a post will encourage continued knowledge sharing.

Ease of Free Riding. A second barrier that informants perceived would impede them from contributing knowledge to a social media in the workplace was the ease of free riding. Informants expressed this view in two ways. First, informants commented that when using social media, it was very easy to benefit from the contributions of others and that the personal benefit they received was in no way related to whether or not they contributed. As one informant in the Marketing division commented, "I'm kind of an eavesdropper on social media sites. I like to see what is going on but I don't like to post. If I don't post, I can still see what's going on, though so I just do that." Hardin (1968) formalized this sentiment as the "tragedy of the commons" in which individuals can take advantage of the largess of others without having to give back for only so long before the common fund is depleted for all. In terms of knowledge contributions, social media in organizations become a place where important knowledge exists for all to use, but if too many people begin to free ride, it ceases to become a useful resource for the common good.

A second way in which informants perceived free riding to be a barrier to knowledge contribution to social media was that if someone who contributed knowledge perceived that other people were free riding, he or she felt little motivation to continue contributing. As one informant from the Analytics division commented, "If I share knowledge with people I'm happy to do it. But if I use a social media tool and then no one is putting anything on there for me to use, I probably will stop putting stuff in there too." Thus, informants who did want to contribute felt that if too much free riding was occurring by others, they would halt their own contributions and keep their knowledge private or at least share it in a private way. 
Research suggests at least two conditions under which people do not free ride and actively contribute to a public good. The first is that they receive some sort of personal benefit from the good (Marwell \& Oliver, 1993). In the context of knowledge sharing, specifically, Fulk et al. (2004) showed that when users of intranet technologies across three organizations perceived that the information contributed by others was personally useful for accomplishing their work tasks they were more likely to contribute information themselves. In such a scenario, perceptions of personal utility of the contributions of others is perhaps a wakeup call to individuals in that they begin to reason, "If the knowledge of others was useful to me, maybe my knowledge will be useful to them." Or, perhaps, acquisition of personally useful knowledge sparks feelings of guilt in the retriever such that he or she feels compelled to add knowledge that may be useful to others.

Social media can be used to overcome tendencies toward free riding by helping individuals to receive personal benefit from the knowledge contributed by others through the use of algorithms that link users to other people and to content. Zhao and Rosen (2009) found that the broadcast nature of microblogging and the use of the technology served as a "People-based RSS feed" that might help "keep a pulse on what is going on in others' minds" (pp. 3, 5). Similarly, at Hewlett Packard a tool that aggregated social media content in the company was viewed by employees as a way to orient themselves in the organization (Brzozowski, Sandholm, \& Hogg, 2009). Another study by Green, Contractor, and Yao (2006) showed how a social networking application with algorithms to make emergent associations between people and usergenerated content spurred cross-boundary interactions and knowledge sharing in environmental engineering and hydrological science research. This increased collaboration occurred because once users learned that others were interested in similar topics to them individuals were more 
willing to work to overcome disciplinary differences and understand one another, even if they did not share a common store of domain knowledge. These findings lead to the following proposition:

Proposition 2a: Social media can demonstrate the personal value of knowledge contributions made by others with algorithms that push notifications of related people and content (e.g. documents, videos, etc.) to individuals.

A second condition under which individuals often stop free riding is when they sense that other people are actively contributing in a particular area in which they are not (Van den Hooff $\&$ de Ridder, 2004). If individuals perceive that others are engaging in conversations or exchanges in which they are not, they will perhaps be more likely to contribute to the conversation if for no other reason than they become worried that they are being left out or that others perceive them to be unimportant. As one informant commented, "sometimes when I use social media I see people talking and I am like 'crap' I need to join this our they'll think I'm a slacker or I'll just be like 'hey, you're missing my opinion'."

A survey of corporate wiki users found that of the many discussions and posts on the wiki, individuals were more likely to contribute to those in which they saw others continuing to contribute, than to those that had not seen contributions in some time (Majchrzak, Wagner, \& Yates, 2006). Similarly, a study of collaboration on Wikipedia showed that articles that are among the most actively revised are the articles that continue to attract the most number of subsequent revisions (Keegan, Gergle, \& Contractor, 2012). In other words, once individuals see that others are contributing in an area about which they have knowledge, they feel more compelled to contribute than when they perceive that discussion in that area is dead. In their study of corporate microbloggers, Schondienst, Krasnova, Gunther, and Riehle (2011) found that 
contributions to active conversations were more likely when employees could easily see which threads were the most active at a given time. Consequently, I propose that:

Proposition 2b: Social media features that easily show people conversations that are active and in which they are not participating will entice them to contribute their own knowledge.

Belief That One's Own Knowledge is not Useful for Coworkers. A third barrier to knowledge contribution identified in this study was informants' beliefs that their own knowledge was not useful to others at American Financial. Comments from informants such as, "Why would anyone care what I think," "I'm new, so it's not like I know anything other people don't," and "I don't have unique knowledge that people can't get from somewhere else," demonstrate this type of thinking. Although most informants indicated that they believed they could learn from the knowledge of others, they were, on the whole, much less convinced that their own knowledge could be useful to others. One informant from the Business Technology division put it bluntly: "I can't see myself sharing anything on A-Life because I don't have anything that other people want."

Over the years, scholars have found that it is often difficult for people to recognize when what they know is unique and different from what others know. This problem is often referred to as "the curse of knowledge." When individuals come to know something well, they can forget that everyone else does not share their knowledge and they neglect to tell people what they know (Heath \& Staudenmayer, 2000). In organizational settings, the problem is amplified with a division of labor that promotes specialization of tasks and staffing plans that place individuals in different departments, sometimes even in diverse geographic locations. The result is that it becomes easy for anyone to think that the knowledge they use daily in their work is commonly held by others and overlook opportunities to actively share it (Louis \& Sutton, 1991). 
One way in which research suggests that people can come to realize that their knowledge is valuable to others is through active feedback giving (Ashford \& Cummings, 1983). Direct feedback from others that one's comments, suggestions, advice were useful is a strong indicator to the contributor of information that his or her knowledge is unique and valuable. The more individuals receive positive formal or informal feedback that their knowledge is valuable, the more likely they are to proactively share knowledge with others (Ashford, Blatt, \& Vande Walle, 2003).

Social media provide various affordances through which people can easily provide feedback about the usefulness of someone's knowledge. For example, a study by Brzozowski, Sandholm, and Hogg (2009) found that blog authors in an organization were motivated to publish more frequently if they saw that others had left many comments on their prior posts (a visible form of information), but the number of actual clicks (not visible) had no effect. In other words, comments were a form of visual feedback that one's comments were read, thought about, and discussed. Similarly, Farzan, DiMicco, and Brownholtz (2009) found that when users of a corporate social networking site were allowed to suggest content to others - and the suggestions were made visible such that the content's producer could see that his or her content was recommended - the content's author would often contribute new content. Thus, given their ability to provide various forms or passive feedback, I propose:

Proposition 3a: The more that individuals receive passive feedback that other social media users are interacting with their knowledge products (through comments, public recommendations, etc.) the more likely they will be to share additional knowledge in the future.

Another way in which people come to realize that their knowledge is useful to others in the organization is when people actively seek it out. Research on advice seeking, for example, shows that people come to understand that they have something unique to contribute to the group 
when others ask them for advice on work related tasks or norms and they also learn that their knowledge is valuable when others openly discuss problems they are having in their work to which they have answers (Rice, Collins-Jarvis, \& Zydney-Walker, 1999). But seekers of knowledge do not always talk about their problems with or ask for advice from holders of knowledge because they are unaware of who those holders are. For this reason, use of social media to discuss problems people are having seems ideal because communication can be broadcast to a wide audience in which a holder of knowledge might exist.

But people often do not want to seek advice or talk about their problems to a wide audience because they fear looking foolish or incompetent to people they do not know. For this reason, Edmondson (1999) has argued that organizations need to create a climate of psychological safety in which people can feel free to discuss, without fear of reproach and ridicule, the fact that they are having certain work related problems they cannot solve. The affordances of social media might be used to create such a culture of public discussion of problems because they provide capabilities for people's nerves about public dissemination of their problems to be calmed. For example, Wattal et al. (2009) found that positive managerial comments about sensitive blog posts in a large multi-national company put people's fears about looking silly in front of peers to rest and encouraged continued participation. By publically responding to someone's post that he or she does not have the knowledge to solve a problem and is looking for help with comments like "great question, I don't know that either. I'd love to see what people come up with" managers might be able to help create a culture in which the psychological safety exists to publically display one's ignorance. Indeed, in a study of the use of social media tools for innovation at MITRE, researchers found that positive public feedback 
from managers on risky proposals elicited more comments on proposals from a wider group of employees (Holtzblatt \& Tierney, 2011). Consequently, I propose:

Proposition 3b: Positive and encouraging public comments by managers through social media on employees' requests for help or admissions that they do not have the knowledge necessary to complete particular work tasks will encourage more people to post such queries, allowing others who have the requested knowledge to realize that their knowledge is indeed useful.

\section{Knowledge Retrieval}

Lack of Awareness of What Knowledge Exists in the Organization. A consistent

finding in research on knowledge management is that people often indicate that they do not seek knowledge from others because they don't know what knowledge people have. This lack of awareness about what it is that other people in the organization know occurs when individuals have impoverished cognitive directories of who knows what (Jackson \& Klobas, 2008). Organizational members are normally better at developing an awareness of what knowledge people in their immediate work groups have than they are of what knowledge is possessed by people in other department or divisions of the company (Hansen, 1999). In short, individuals often have an insular view of the organization. Consequently, individuals may not turn to social media as places where they can retrieve knowledge from others because they are unaware that there might be knowledge worth retrieving.

A common suggestions made by researchers is that to overcome insular views of what people in the organization know, management should formally encourage cross-functional project work to get people familiar with others across the organization (Jassawalla \& Sashittal, 1999) of encourage people to cultivate informal network connections with individuals in other business units (Burt, 2004). But cross-functional project teams are not an option for every 
employee, and it takes a good deal of effort and the right type of personality to be able to form informal network connections with people whom one does not regularly come into contact.

Social media may be useful for encouraging people to come into contact that might not have the formal excuse or the informal motivation to otherwise do so. For example, at IBM research shows that blogs are often used by workers to advertise ideas to others with whom they might not otherwise come into contact, such as managers outside one's work group (Farrell et al., 2008). In another study at IBM, researchers found that the use of a corporate social networking site helped employees strengthen associations with individuals about whom they know little about, and, unlike in non-organizational contexts, there was less social network site activity among close, co-located colleagues (DiMicco et al., 2009). The affordances of social media tools, like recommender functions and algorithms that make suggestions for connections to people or content based on similarities in search patterns, docuemnts read, or other metrics may also help individuals become aware of what people in other departments know and, conseqeuntly, overcome their insular view of the organization. For example a study of microblog use in an organization noted that the technology recommended certain people for users to follow, and that this feature was key to managing the content in the system (Zhang et al., 2010). In a study a study of an application driven by an algorithm that matched blog authors with certain topics of interest Dugan, Geyer, and Millen (2010) found that use generated increased traffic and communication among users who were previously unknown to each other. These findings suggest that:

Proposition 4a: Algorithms that push content at users or recommend people for users to get to know based on similarity in tasks, projects, or other work-related attributes (as opposed to simply similarities of social connections) will help users see the value of social media for retrieving knowledge. 
Research suggests that another reason people do not actively look for knowledge across the organization is that they are already overloaded with information and they do not have the patience or stamina to process more (Dabbish \& Kraut, 2006). One solution to the problem of information overload appears to be connecting people with relevant information, instead of simply connecting them with more information. People are willing to look at new information or data, even if they feel overwhelmed, if they perceive that it will have immediate value for their work (Haas, 2006). Here again, some affordances of social media may be useful.

Research has suggested that user generated social tags and folksonomies with which to classify information can aid people to quickly find relevant information. For example, when conducting searches for information, a study found that workers at IBM reused social tags already in a system and consulted other individuals' lists of tags because doing so provided faster access to relevant information than broad search (Millen \& Feinberg, 2006). The study also found that nearly all individuals using a social tagging application looked at the tags or bookmarks of other individuals at some point. In another study, use of keywords and tags in wiki entries were seen as way for users to view the explicit connections among projects (Ding et al., 2007). When individuals begin to tag content similarly or learn how others tag content, they can find relevant information faster. Additionally, this principle that well-crafted labels can improve knowledge classification is supported by research on social bookmarking in corporate settings, which found that when users anticipated how others would find information and shaped contributions accordingly, those others found content that was useful that they would not have thought to search for in a broadcast search (Thom-Santelli, Muller, \& Millen, 2008). For these reasons, it seems possible that:

Proposition 4b: Spreading the use of emergent tags or folksonomies across the organization will not only help people find relevant knowledge faster, 
but also help them to stumble across relevant content that they might not have known existed.

Preference for Knowledge from People Who are Known Personally. Informants in this study voiced a clear preference for retrieving knowledge from people as opposed to databases, documents, or other repositories. As one informant from the Operations division commented, "I would rather talk to someone and learn from them then try to read something that they posted on a social media tool." Another informant from Business Technology expressed a similar view: "There's even things that are basic that you have a manual for. I don't want to read the manual. I want to someone to explain it to me so I can ask questions if I don't get it and I can see from them by looking at them if the manual is really right of if it is just corporate speak." This finding is somewhat surprising given that a good deal of prescriptive research suggests that individuals should be more comfortable retrieving explicit knowledge from databases and repositories than tacit knowledge (Hansen, Nohria, \& Tierney, 1999). Yet even most individuals in this study who worked primarily with explicit and codified knowledge (like those individuals in Operations and Business Technology) expressed a clear preference for retrieving knowledge from people, rather than from social media tools. Perhaps this finding can be explained, in part, by this observation from an informant in the Operations division: "As a new employee you want to make sure you get the right knowledge. It's easier to know that if you know the person who is giving it to you and you trust them." For this reasons a number of informants shared similarly strong views to one new employee in the Consumer Relations division: "I won't use A-Life to get knowledge. I'll just go to people instead and talk to them. It's always better."

Indeed, a long history of research dating back to the 1950s shows that individuals tend to use information more if they like and trust its source. Zajonc's (1980) observations of the "mere exposure effect" provide a compelling example. He argued that not all feelings (preferences) are 
based on cognitive processes, but often precede them. Affect does not require extensive cognitive processing to occur. When people are exposed to a certain image or sound they come to like that image or sound simply due to their mere exposure to it. The effect holds for people as well. Individuals show an increasingly preference for people that they have seen before and know something about. As Zajonc showed in a review of studies, once preferences are established based on mere exposure they are less likely to be changed than cognitions. Even after complete removal of causal effects (as in subject debriefings), people's feelings and opinions often remain. Research suggests that in the context of information retrieval, individuals are more likely to trust content from people from whom they have seen content before, rather than people from whom they are seeing content for the first time, and even more likely to trust and like that content if they trust and like the person who supplied it (Phillips et al., 2004).

If people express a preference to retrieve knowledge from people they know personally over knowledge retrieval from an electronic repository, and they are more likely to trust and value knowledge from others they have seen before and know something about, social media affordances may be useful for promoting knowledge retrieval. A study of corporate social networking sites found that individuals were more likely to reuse information provided by other people in their personally-defined social network than other people at the company (Mejova et al., 2011). In other words, they were more likely to retrive knowledge contribtued by someone who they, at one point in time, felt they knew, than they were from some random coworker.

More to the point, a study on the construction of personal profiles and photo sharing provides a compelling example of the power of liking knowledge contributed by people who are known personally. Thom-Santelli and Millen (2009) describe a photo sharing feature built into a prototype social networking site utilized within IBM's R\&D division. The research found that 
when newcomers to the organization looked at personal photos posted by their coworkers, they felt that coworkers were more approachable and they liked them more. In a follow-up analysis, Millen (2010) discussed anecdotal evidence that individuals who viewed people's personal photos were also more likely to retrive the work related knowledge they posted. Seeing personal information about a coworker that one did not know personalized the coworker and increasd liking. Increased liking of the person translated into increased liking of knowledge that they contributed through communications on the social networking tool. When the social networking site moved out of prototype phase and was implemented across the entire organization, the photo sharing feature was not included and rates of knowledge retrieval from unknown others diminished. Leonardi and Meyer (2015) found similar dynamics in their study of the use of a social networking site at a large telecommunications company. Employees who made contact with coworkres on the tool most often did so after learningn about personal information about the employee. As the authors demonstrated, personal information about coworkers from whom one wanted knowledge provided the "social lubrication" necessary to feel comfortable approaching a colleague, building a relationship with them and, later, asking them to take time to share tacit knoweldge. Because social media can be used for informal communication and sharing of personal as well as professional information, they have the potential to encourage work related knowledge sharing by allowing retreivers to "get to know" a contributor:

Proposition 5: $\quad$ Social media users who are exposed to personal information (e.g. narratives, photos, etc.) by coworkers who are otherwise unknown to them will be more likely to retrieve work-related knowledge from those coworkers.

\section{Conclusion}

I began this paper by suggesting that social media tools might encourage and aid knowledge sharing within large organizations because they are leaky pipes for communication. If 
organizations can, through the implementation of social media, allow employees to share knowledge without having to document their work in great detail, log-in and file that documentation on some server or in some tool that they rarely use; but, instead do nothing more than communicate with others and the knowledge embedded in that communication would leak out to the rest of the organization, knowledge sharing might unfold more effortlessly and often. If Kane (2017) is right that social media will usher in an era of leaky knowledge, it seems likely that their effects on knowledge sharing in organizations would not be simply evolutionary, as he suggests, but revolutionary. Enabling knowledge to leak out from the pipes through which it travels to distant corners of the organization - and to vistas beyond the organization - presents a whole new set of opportunities and challenges for the management of organizational knowledge.

Yet for such a revolution to occur, individuals need to willingly contribute knowledge by communicating with others through social media and following the communications of others so that they can retrieve knowledge. Although the motivation of contribution and retrieval is a perennial obstacle for knowledge sharing, I have suggested that the affordances of the social media that are just now entering many workplaces may provide unique and improved abilities at overcoming these obstacles. I submit the propositions generated in this paper as an initial step in theoretical development on the role of social media for organizational knowledge sharing and encourage studies that would begin to test these propositions and their derivatives in empirical contexts. 


\section{Acknowledgements}

Generous funding that was used to support the writing of this article was provided by two grants from the National Science Foundation (SES-1331492 and ACI-1322103). I wish to thank Elizabeth Davidson and Jeffrey Treem for helpful comments that have improved this article. 


\section{References}

Alavi, M., \& Leidner, D. E. (2001). Review: Knowledge management and knowledge management systems: Conceptual foundations and research issues. MIS Quarterly, 25(1), 107.

Ashford, S. J., Blatt, R., \& Vande Walle, D. (2003). Reflections on the looking glass: A review of research on feedback-seeking behavior in organizations. Journal of Management, 29(6), 773-799.

Ashford, S. J., \& Cummings, L. L. (1983). Feedback as an individual resource: Personal strategies of creating information. Organizational Behavior and Human Performance, 32(3), 370398.

Brzozowski, M., Sandholm, T., \& Hogg, T. (2009). Effects of feedback and peer pressure on contributions to enterprise social media Proceedings of the 2009 International Conference on Supporting Group Work (pp. 61-70). doi:10.1145/1531674.1531684

Burt, R. S. (2004). Structural holes and good ideas. American Journal of Sociology, 110(2), 349399.

Choi, S. Y., Lee, H., \& Yoo, Y. (2010). The impact of information technology and transactive memory systems on knowledge sharing, application, and team performance: A field study. MIS Quarterly, 34, 855-870.

Chui, M., Manika, J., Bughin, J., Dobbs, R., Roxburgh, C., Sarrazin, H., . . Westergren, M. (2012). The social economy: Unlocking value and productivity through social technologies: McKinsey Global Institute.

Cress, U., Kimmerle, J., \& Hesse, F. W. (2006). Information exchange with shared databases as a social dilemma: The effect of metaknowledge, bonus systems, and costs. Communication Research, 33, 370-390. doi: 10.1177/0093650206291481

Dabbish, L., \& Kraut, R. (2006). Email overload at work: An analysis of factors associated with email strain. Proceedings of The ACM Conference on Computer Supported Cooperative Work (CSCW 2006), 431-440.

DiMicco, J., Geyer, W., Millen, D. R., Dugan, C., \& Brownholtz, B. (2009). People sensemaking and relationship building on an enterprise social networking site Proceedings of the 42nd Annual Hawaii International Conference on System Sciences doi:10.1109/HICSS.2009.343

Ding, X., Danis, C., Erickson, T., \& Kellogg, W. A. (2007). Visualizing an enterprise wiki Proceedings of CHI '07 Extended Abstracts on Human Factors in Computing Systems (pp. 2189-2194). doi:10.1145/1240866.1240978

Dugan, C., Geyer, W., \& Millen, D. R. (2010). Lessons learned from blog muse: Audience-based inspiration for bloggers Proceedings of the 28th International Conference on Human Factors in Computing Systems (pp. 1965-1974). doi:10.1145/1753326.1753623

Edmondson, A. C. (1999). Psychological safety and learning behavior in work teams. Administrative Science Quarterly, 44, 350-383.

Ehrlich, K., \& Shami, N. S. (2010). Microblogging inside and outside the workplace Proceedings of the Fourth International Conference on Weblogs and Social Media (pp. 42-49).

Ellison, N. B., Gibbs, J. L., \& Weber, M. S. (2015). The use of enterprise social network sites for knowledge sharing in distributed organizations: The role of organizational affordances. American Behavioral Scientist January 59, 103-123.

Erickson, T., \& Kellogg, W. (2000). Social translucence: An approach to designing systems that support social processes. ACM Transactions on Computer-Human Interaction, 7, 59-83. 
Farrell, R. G., Kellogg, W., \& Thomas, J. C. (2008). The participatory web and the socially resilient enterprise Computer-Supported Cooperative Work

Farzan, R., DiMicco, J., Millen, D. R., Brownholtz, B., Geyer, W., \& Dugan, C. (2008). Results from deploying a participation incentive mechanism within the enterprise Proceedings of the Twenty-Sixth Annual SIGCHI Conference on Human factors in Computing Systems (pp. 563-572). doi:10.1145/1357054.1357145

Farzan, R., DiMicco, J. M., \& Brownholtz, B. (2009). Spreading the honey: A system for maintaining an online community Proceedings of the 2009 International Conference on Supporting Group Work (pp. 31-40). doi:10.1145/1531674.1531680

Fulk, J., Heino, R., Flanagin, A. J., Monge, P. R., \& Bar, F. (2004). A test of the individual action model for organizational information commons. Organization Science, 15(5), 569-585. doi: $10.1287 /$ orsc. 1040.0081

Gammelgaard, J. (2007). Why not use incentives to encourage knowledge sharing? Journal of Knowledge Management Practice, 8(1).

Glaser, B. (1978). Theoretical sensitivity. Mill Valley, CA: The Sociological Press.

Green, H. D., Contractor, N., \& Yao, Y. (2006). C-iknow: Cyberinfrastructure knowledge networks on the web. A social network enabled recommender system for locating resources in cyberinfrastructures. . Paper presented at the annual meeting of the American Geophysical Union, San Francisco, CA.

Haas, M. R. (2006). Knowledge gathering, team capabilities, and project performance in challenging work environments. Management Science, 52(8), 1170-1184.

Hansen, M. T. (1999). The search-transfer problem: The role of weak ties in sharing knowledge across organization subunits. Administrative Science Quarterly, 44(1), 82-111.

Hansen, M. T., Nohria, N., \& Tierney, T. (1999). What's your strategy for managing knowledge. Harvard Business Review, 77(2), 106-116.

Hardin, G. (1968 ). The tragedy of the commons. Science, 162, 1243-1248.

Heath, C., \& Staudenmayer, N. (2000). Coordination neglect: How lay theories of organizing complicate coordination in organizations. Research in Organizational Behavior(22), 153191.

Heinz, M., \& Rice, R. E. (2009). An integrated model of knowledge sharing in contemporary communication environments. In C. S. Beck (Ed.), Communication yearbook (Vol. 33, pp. 134-175). NY: Routledge.

Holtzblatt, L., \& Tierney, M. L. (2011). Measuring the effectiveness of social media on an innovation process Proceedings of the 2011 Annual Conference Extended Abstracts on Human Factors in Computing Systems (pp. 697-712). doi:10.1145/1979742.1979669

Holtzblatt, L. J., Damianos, L. E., \& Weiss, D. (2010). Factors impeding wiki use in the enterprise: A case study Proceedings of the 28th International Conference Extended Abstracts on Human Factors in Computing Systems (pp. 4661-4676). doi:10.1145/1753846.1754208

Huber, G. P. (1991). Organizational learning: The contributing processes and the literatures. Organization Science, 2(1), 88-115.

Jackson, P., \& Klobas, J. (2008). Transactive memory systems in organizations: Implications for knowledge directories. Decision Support Systems, 44(2), 409-424.

Jarrahi, M. H., \& Sawyer, S. (2013). Social technologies, informal knowledge practices, and the enterprise. Journal of Organizational Computing and Electronic Commerce, 23(1), 110137. 
Jassawalla, A. R., \& Sashittal, H. C. (1999). Building collaborative cross-functional new product teams. Academy of Management Executive, 13(3), 50-63.

Kane, G. C. (2017). The evolutionary implications of social media for organizational knowledge management. Information and Organization.

Keegan, B., Gergle, D., \& Contractor, N. (2012). Do editors or articles drive collaboration? Multilevel statistical network analysis of wikipedia coauthorship. Proceedings of the 12th annual Conference on Computer Suporterd Cooperative Work 1-10.

Kvale, S. (1996). Interviews: An introduction to qualitative research interviewing. Thousand Oaks, CA: Sage.

Lave, J., \& Wenger, E. (1991). Situated learning: Legitimate peripheral participation. Cambridge: Cambridge University Press.

Lenhart, A., Purcell, K., Smith, A., \& Zickuhr, K. (2010). Social media and young adults. Retrieved from Pew Internet and American Life Project's website: http://www.pewinternet.org/Reports/2010/Social-Media-and-Young-Adults.aspx.

Leonardi, P. M. (2014). Social media, knowledge sharing, and innovation: Toward a theory of communication visibility. Information Systems Research, 25(4), 796-816.

Leonardi, P. M. (2015). Ambient awareness and knowledge acquisition: Using social media to learn "who knows what" and "who knows whom". MIS Quarterly, 39(4), 747-762.

Leonardi, P. M., Huysman, M., \& Steinfield, C. (2013). Enterprise social media: Definition, history, and prospects for the study of social technologies in organizations. Journal of Computer-Mediated Communication., 19(1), 1-19.

Leonardi, P. M., \& Meyer, S. R. (2015). Social media as social lubricant: How ambient awareness eases knowledge transfer. American Behavioral Scientist, 59(1), 10-34.

Leonardi, P. M., \& Rodriguez-Lluesma, C. (2012). Sociomateriality as a lens for design: Imbrication and the constitution of technology and organization. Scandinavian Journal of Information Systems, 24(2), 79-88.

Leonardi, P. M., \& Rodriguez-Lluesma, C. (2013). Occupational stereotypes, perceived status differences, and intercultural communication in global organizations. Communication Monographs, 70(4), 478-502.

Leonardi, P. M., \& Treem, J. W. (2012). Knowledge management technology as a stage for strategic self-presentation: Implications for knowledge sharing in organizations. Information and Organization, 22(1), 37-59.

Leonardi, P. M., \& Vaast, E. (2017). Social media and their affordances for organizing: A review and agenda for research. Academy of Management Annals, 11(1), 150-188.

Louis, M. R., \& Sutton, R. I. (1991). Switching cognitive gears: From habits of mind to active thinking. Human Relations, 44, 55-76.

Majchrzak, A., Faraj, S., Kane, G. C., \& Azad, B. (2013). The contradictory influence of social media affordances on online communal knowledge sharing. Journal of Computer Mediated Communication, 19(1), 38-55.

Majchrzak, A., Wagner, C., \& Yates, D. (2006). Corporate wiki users: Results of a survey Proceedings of the 2006 International Symposium on Wikis (pp. 99-104). doi:10.1145/1149453.1149472

Marwell, G., \& Oliver, P. (1993). The critical mass in collective action: A micro-social theory. New York: Cambridge University Press.

Mejova, Y., Schepper, K. D., Bergman, L., \& Lu, J. (2011). Reuse in the wild: An empirical and ethnographic study of organizational content reuse Proceedings of the 2011 Annual 
Conference on Human factors in Computing Systems (pp. 2877-2886).

doi:10.1145/1978942.1979370

Millen, D. R. (2010). Social computing in the global workplace: Connecting people and connecting work. Paper presented at the Technology and Social Behavior Colloquium, Northwestern University.

Millen, D. R., \& Feinberg, J. (2006). Using social tagging to improve social navigation. Proceedings of the Workshop on the Social Navigation and Community-based Adaption Technologies

Nicolini, D. (2012). Practice theory, work, and organization. Oxford: Oxford University Press.

Nicolini, D., Gherardi, S., \& Yanow, D. (2003). Toward a practice-based view of knowing and learning in organizations. In D. Nicolini, S. Gherardi \& D. Yanow (Eds.), Knowing in organizations: A practice-based approach (pp. 3-31). New York: M.S. Sharp.

Orlikowski, W. J. (2002). Knowing in practice: Enacting a collective capability in distributed organizing. Organization Science, 13(3), 249-273.

Phillips, K. W., Mannix, E. A., Neale, M. A., \& Gruenfeld, D. H. (2004). Diverse groups and information sharing: The effects of congruent ties Journal of Experimental Social Psychology, 40(4), 497-510.

Rice, R. E., Collins-Jarvis, L., \& Zydney-Walker, S. (1999). Individual and structural influences on information technology helping relationships. Journal of Applied Communication Research, 27(4), 285-309.

Schondienst, V., Krasnova, H., Gunther, O., \& Riehle, D. (2011). Micro-blogging adoption in the enterprise: An empirical analysis Proceedings of the 10th International Conference on Wirtschaftsinformatik

Strauss, A., \& Corbin, J. (1998). Basics of qualitative research: Techniques and procedures for developing grounded theory (2nd ed.). Thousand Oaks, CA: Sage.

Thom-Santelli, J., \& Millen, D. R. (2009). Learning by seeing: Photo viewing in the workplace. Proceedings of CHI 2009: ACM Conference on Human Factors in Computing Systems, 110.

Thom-Santelli, J., Muller, M. J., \& Millen, D. R. (2008). Social tagging roles: Publishers, evangelists, leaders Proceeding of the Twenty-Sixth Annual SIGCHI Conference on Human Factors in Computing Systems (pp. 1041-1044). doi:10.1145/1357054.1357215

Treem, J. W., \& Leonardi, P. M. (2012). Social media use in organizations: Exploring the affordances of visibility, editability, persistence, and association. Communication Yearbook, 36, 143-189.

Van den Hooff, B., \& de Ridder, J. A. (2004). Knowledge sharing in context: The influence of organizational commitment, communication climate and cmc use on knowledge sharing. Journal of Knowledge Management, 8(6), 117-130.

Wasko, M. M., \& Faraj, S. (2005). Why should i share? Examining social capital and knowledge contribution in electronic networks of practice. MIS Quarterly, 29(1), 35-57.

Wattal, S., Racherla, P., \& Mandviwalla, M. (2009). Employee adoption of corporate blogs: A quantitative analysis Proceedings of the 42nd Annual Hawaii International Conference on System Sciences doi:10.1109/HICSS.2009.188

Wenger, E. (2000). Communities of practice and social learning systems. Organization, 7(2), 225246.

Yuan, Y. C., Fulk, J., Monge, P. R., \& Contractor, N. (2010). Expertise directory development, shared task interdependence, and strength of communication network ties as multilevel 
predictors of expertise exchange in transactive memory work groups. Communication Research, 37, 20-47. doi: 10.1177/0093650209351469

Zajonc, R. B. (1980). Feeling and thinking: Preferences need no inferences. American Psychologist, 35, 151-175.

Zhang, J., Qu, Y., Cody, J., \& Wu, Y. (2010). A case study of micro-blogging in the enterprise: Use, value, and related issues Proceedings of the 28th International Conference on Human Factors in Computing Systems (pp. 123-132). doi:10.1145/1753326.1753346

Zhao, D., \& Rosson, M. B. (2009). How and why people twitter: The role that micro-blogging plays in informal communication at work Proceedings of the 2009 International Conference on Supporting Group Work (pp. 243-252). doi:10.1145/1531674.1531710 
Table 1

Barriers to Knowledge Sharing and Potential for Social media to Help Overcome Them

\begin{tabular}{|c|c|c|c|c|}
\hline \multicolumn{2}{|c|}{ Barriers Discussed by Employees } & \multirow{2}{*}{$\begin{array}{l}\text { Theory about why barrier } \\
\text { exists/persists }\end{array}$} & \multirow{2}{*}{$\begin{array}{l}\text { Theoretical mechanisms } \\
\begin{array}{c}\text { suggesting how barrier can be } \\
\text { overcome }\end{array} \\
\begin{array}{l}\text { Public recognition (from } \\
\text { management and/or coworkers) }\end{array}\end{array}$} & \multirow{2}{*}{ 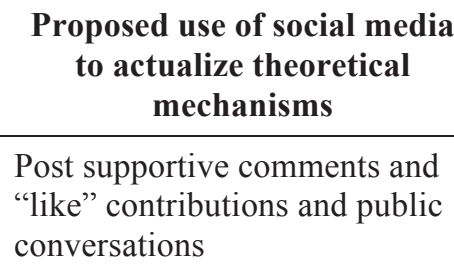 } \\
\hline $\begin{array}{l}\text { Knowledge } \\
\text { Contribution }\end{array}$ & Lack of Incentive & & & \\
\hline & Ease of free riding & $\begin{array}{l}\text { Perception of lack of requirement of } \\
\text { participation to receive gain from } \\
\text { others }\end{array}$ & $\begin{array}{l}\text { Make people see personal benefit of } \\
\text { others' contributions }\end{array}$ & $\begin{array}{l}\text { Use algorithms that push } \\
\text { notifications of similar people } \\
\text { and content }\end{array}$ \\
\hline & & & $\begin{array}{l}\text { Help people notice that others are } \\
\text { actively contributing in a particular } \\
\text { area }\end{array}$ & $\begin{array}{l}\text { Highlight active content and } \\
\text { conversations for relevant users }\end{array}$ \\
\hline & $\begin{array}{l}\text { Belief that one's own } \\
\text { knowledge is not useful }\end{array}$ & Curse of knowledge & Provide feedback on contributions & $\begin{array}{l}\text { Provide public recognition of } \\
\text { utility of contributions }\end{array}$ \\
\hline & & & $\begin{array}{l}\text { Promote culture of discussion of } \\
\text { problems }\end{array}$ & $\begin{array}{l}\text { Public managerial support for } \\
\text { problems looking for solutions }\end{array}$ \\
\hline \multirow[t]{3}{*}{$\begin{array}{l}\text { Knowledge } \\
\text { Retrieval }\end{array}$} & $\begin{array}{l}\text { Lack of awareness of } \\
\text { what knowledge is out } \\
\text { there }\end{array}$ & Insular view of the organization & $\begin{array}{l}\text { Encourage inter-departmental } \\
\text { communication }\end{array}$ & $\begin{array}{l}\text { Use algorithms that push } \\
\text { notifications of similar people } \\
\text { and content }\end{array}$ \\
\hline & & Information overload & $\begin{array}{l}\text { Connect people with relevant } \\
\text { information }\end{array}$ & $\begin{array}{l}\text { Spread use of emergent tags or } \\
\text { folksonomies }\end{array}$ \\
\hline & $\begin{array}{l}\text { Preference for knowledge } \\
\text { from people who are } \\
\text { known personally }\end{array}$ & $\begin{array}{l}\text { People like and trust information if } \\
\text { they like the like and trust its source }\end{array}$ & Personalize information & $\begin{array}{l}\text { Encourage sharing of non-work } \\
\text { related content in order to seed } \\
\text { work-related interactions }\end{array}$ \\
\hline
\end{tabular}


Table 2

Differences in Perceptions of "Lack of Incentive" Barrier

\begin{tabular}{llll}
\hline Perception of Barrier & \multicolumn{3}{c}{ Belief about Value of Social media in Workplace } \\
\hline & Positive $(n=13)$ & Neutral $(n=21)$ & Negative $(n=26)$ \\
\cline { 2 - 4 } High & 1 & 18 & 25 \\
Low & 12 & 3 & 1 \\
\hline
\end{tabular}

Note: Numbers in cells indicate number of informants in each category who mentioned lack of incentive as either a high or a low barrier to contributing knowledge to a social media 